\section{Is the Public Good Role of Higher Education Under Attack?}

\section{Ellen Hazelkorn}

Ellen Hazelkorn is professor emerita and former director of the Higher Education Policy Research Unit (HEPRU), Ireland, and international coinvestigator, ESRC/HEFCE-funded Centre for Global Higher Education, London, UK. E-mail: ellen.hazelkorn@dit.ie.

$\mathrm{H}$ igher education is usually seen as serving the public good, especially when it is funded directly by the state, and because its benefits extend to the individual and society. It is the source of human capital, innovation, and entrepreneurship to fuel and sustain personal, social, and economic ambitions and development that society and citizens require while underpinning civil society. As such, there is an implicit social contract that balances public support, through taxation and public policy, in return for institutional autonomy.

Civic and land grant universities, in the United Kingdom and the United States and other regions and countries, are a good example of this balance. Universities were established to deliver "publically articulated purposes," while the academy retained a strong role in determining and asserting quality and value. There has been an underlying assumption that by representing and promoting the public good through teaching, research, and service/engagement, the actions and outcomes of (public) universities were ipso facto in the public interest.

Today, many assumptions that have underpinned public support for higher education investment have not held true. At a time when higher education is in growing demand, more people feel left behind-struggling to live up to societal and personal expectations. Unequal distribution of societal goods has been accompanied by a perception that the rest of the world is doing better. Economic and research, development, and innovation (RDI) benefit is insufficiently impactful beyond the metropoles. Moreover, we are competing with cities and countries that most of us never knew of or previously considered.

UK and US based surveys suggest that universities and faculty are regarded as too self-serving and insufficiently interested in student learning or outcomes. While the university community is gripped by its position in global rankings, fewer than I percent of US students attend highly selective universities such as Harvard and Yale, and only 9 percent of UK students attend Oxbridge or Russell Group universities.
These contrasting world visions are evidenced in recent election results in the United Kingdom, the United States, and France, and rising social tensions elsewhere. They show a widening gap between universities and people living in global-facing towns and cities, and locally focused communities and regions.

\section{Tensions between Higher Education and Society}

Across Europe, and elsewhere, higher education is under pressure.

- In the United States, accreditation has traditionally been the shared responsibility of a "triad" comprised of the federal government, regional accrediting agencies, and state governments, with the critical support of the academy. The federal government's role has been relatively minor. However, over the years, there has been growing concern about student completion and employability, especially when seen in the context of rising university prices and student debt. The Obama administration created the College Scorecard "to hold colleges accountable for cost, value, and quality" and open up higher education performance to public scrutiny. In addition, there are several actions at the congressional level aimed at tightening up accreditation practices and the practices of accreditors.

- In the United Kingdom, the first version of the Teaching Excellence Framework (TEF) has been published. Its purpose is to provide students with better information about the quality of degree programs and to raise the profile of teaching. To some extent, the TEF supplants the previous practice of quality assurance (QA), which produced lengthy reports for institutions and was accordingly unsuitable for measuring and comparing student performance and outcomes. QA has often been criticised for being too bureaucratic and a box-ticking exercise. These developments have contributed to a breakdown in trust and a gap that rankings have filled. The TEF speaks to a range of needs and interests, including a more sceptical political system and public, and a diverse educational market.

- In Ireland, the government set out its vision for higher education in the National Strategy for Higher Education to 2030 (20II). Shaped by an expert group following lengthy consultation, it promoted the concept of the "system-as-a-whole," in contrast to the view frequently promulgated by university rankings, which elevates the performance of indi- 
vidual institutions. The strategy also acknowledged the constraints of the country's size and budget. The government seeks to hold institutions to account through a negotiated process called "Strategic Dialogue," to ensure better alignment between institutional mission and performance and overall national policy objectives. A research prioritization strategy has also been adopted, linking funding to key industrial sectors.

\section{Today, many assumptions that have un- derpinned public support for higher ed- ucation investment have not held true.}

- In the Netherlands, a series of events led, over recent decades, to greater government involvement with the intention to make universities more productive and efficient, and to introduce the principle of long-range scientific planning. This followed concerns around institutional differentiation and student performance, especially poor retention and the inability of the system to meet the varied needs of students and labour markets. Universities and universities of applied sciences have both signed collective strategic agreements with the relevant government ministries through their associations, which have provided the framework for these agreements. The agreements, made by individual higher education institutions, include statements and targets around system structure, institutional profiles, and programs, and are linked to funding.

\section{Time for a New Social Contract?}

These examples illustrate just some ways in which growing tensions between higher education and society, often described in terms of (social) accountability vs. (institutional) autonomy, are becoming both more visible and, at times, contentious. Recent events and decisions in Hungary, India, and Turkey worryingly expose a different set of fissures. However, collectively, all these instances raise questions about higher education's role in society today, and how the "public good" is determined in practice by universities, governments, and the public.

Government "incursions" into domains traditionally associated with academic self-governance, such as focusing on performance and outcomes, is often presented as evidence of neoliberal new public management (NPM). More recently, nationalist and nativist thinking and policies have put higher education at odds with governments, which have campaigned to restrict foreigners, stem multiculturalism, and question liberal social values. These "ideological" developments have enabled the academic community to brush aside genuine criticism, thus feeding public concerns about higher education's arrogance and isolationism.

Ireland is again an interesting case in point. Failure by one university to respond to legitimate allegations of financial irregularities by whistle-blowers has led to the entire sector coming under public scrutiny. In turn, universities have argued that declining public funding has transformed public institutions into private ones, thus altering the governance model. However, in doing so, the universities have effectively recast their "public good" role as a transactional relationship-opening up a can of worms.

Over recent decades, we have witnessed a significant shift in governance arrangements, from strict regulation to steering-at-a-distance, to signs of a new social contract. The latter model involves higher education institutions and governments coming together to form a common vision with agreed outcomes. Such practices are underway in, inter alia, Australia, Hong Kong, Ireland, the Netherlands, New Zealand, Norway, and Ontario. The process shows the potential that different goals need not be mutually exclusive, and that being responsive to society can give the academy's own goals legitimacy in a wider sense.

Whereas the state historically provided for the needs of universities, today - in the age of globalization and nearuniversal higher education-higher education institutions provide for the needs of society. In this new environment, higher education can choose to engage meaningfully in helping to construct the new social contract or the state will step in - taking full responsibility to itself.

DOI: http://dx.doi.org/I0.60I7/ihe.20I7.9I.10055

\section{"Free Speech" and "Offen- sive" Speech on Campus}

\section{Peter Scott}

Peter Scott is professor of higher education studies at the University College London Institute of Education, UK. He is also the Commissioner for Fair Access for Scotland. E-mail: p.scott@ioe.ac.uk.

$T$ Threats to free speech and academic freedom are legion-from authoritarian regimes in China, Hungary, Russia, and Turkey, and Middle-East states beleaguered by religious fundamentalism, to right-wing populists who believe their cultures and communities are under attack (and 